\title{
SOBRE LA COORDINACION ENTRE LOS MEDIOS DE COMUNICACION SOCIAL
}

Juan Beneyto

\section{Coexistencia}

Si hace algunos años pudo hablarse del periódico impreso como del horizonte sin azul del hombre contemporáneo, a las gentes del tiempo presente lo que les cierra aquel horizonte desde la infancia es la Televisión y lo que acaba con los espacios libres es la Publicidad. Se ha dicho agudamente a este último respecto que el aire que respiramos es un compuesto de nitrógeno, oxígeno y publicidad, notablemente impulsado por la contaminación. Incluso el espacio urbano anda desapareciendo bajo la irrupción de los carteles anunciadores, al igual que el espacio rural se encuentra amenazado, tras haber sido empapeladas las zonas turísticas...

Al libro y el periódico, como información impresa, único medio de difusión por procedimientos multiplicadores, se han añadido la Radio, el Cine y la Televisión, trinidad técnica que ha hecho concurrencia al medio tradicional, a pesar del esfuerzo de éste para mostrarse más ágil y más rápido.

El fogonazo del brillo de alguno de los nuevos instrumentos hace olvidar que no son otra cosa que medios técnicos, colocados tras la cinta, el disco, la estereotipia, el hueco o el facsímil... Como en otro orden no es distinto el puesto del automóvil o del avión que el de los faetones y las diligencias. Unos y otros se distinguen esencialmente por la velocidad y la comodidad. 
Precisamente ese instrumento arrollador cumple — según la observación común - la última etapa: la televisión hace culminar el arte de comunicarnos. No sólo nos ahorra esfuerzo, sino que abole el tiempo y el espacio, y se presenta como síntesis de los anteriores lenguajes, es imagen y sonido, gesto y color.

No hay que extrañarse, en consecuencia, que el referido fogonazo pese en las actitudes del público. La oficina informativa de la televisión norteamericana hizo público en 1975 el esquema general de las actitudes humanas en relación con los distintos instrumentos entre 1959 y 1974. La conclusión es que hoy la televisión ocupa el primer lugar, manteniendo la posición lograda en 1963. La misma prensa, fórmula tradicional de comunicación informativa, se encuentra desde esa fecha al nivel de un 47 por 100 . $\mathrm{Y}$ desde 1975 el 51 por 100 de los encuestados norteamericanos estima más fiable la televisión que la prensa ${ }^{1}$.

El enfrentamiento Prensa-Televisión, patente a partir de $1959^{2}$, se ha mostrado efectivo, y el ataque del medio más moderno se ha of recido como un desafío desenvuelto a gran velocidad ${ }^{3}$. Una de sus más radicales consecuencias se produce en los países subdesarrollados. Donde era de esperar una alfabetización y una consiguiente formación de públicos de lectores, la televisión ha cortado el esquema clásico, centrándose en el medio electrónico del modo cómo en los países industrializados se había centrado en el tipográfico. Además, la televisión ha venido a sustituir a la familia y a la escuela al transformarse de un medio informativo en un medio educativo e integrador.

Pero aun reduciendo nuestra consideración al mundo más próximo, es evidente que los titulares de la prensa dejan de ser frescos cuando podemos leerlos: recogen noticias ya vistas u oídas. Por el contrario, en el diario impreso podemos leer más cosas de las que vemos u oímos en el electrónico. La televisión es un medio limitado por el tiempo. Las informaciones no pueden ocupar la extensión que es dable en el diario. En lo que la televisión gana es en la zona del entretenimiento, como espectáculo y como distracción: relata lo importante (el detalle hay que leerlo en la prensa), nos avanza la noticia y la amplifica con la imagen, el sonido, el color y el movimiento.

Con todo, ni la televisión ha barrido a la radio - como pensaban expertos británicos con quienes hube de comentar la situación a fines de 1957-, ni ha devorado a la prensa. Los distintos medios se han visto como coexistentes,

Datos del "Television information office", noviembre 1975. El informe se debe a la Roper Organisation Inc.

2 La primera llamada de atención en el Congreso mundial de Prensa en Columbia (Misuri), marzo de 1959. Poco antes la compañía inglesa Beaverbrook, en su informe anual de 1957, ya lo señalaba. Cf. Daily Express 22 de febrero de 1958.

"Así John Burgess, del grupo inglés Cumberland, en su informe a la Federación Internacional, 1974. 
pero también como complementarios ${ }^{4}$. Quizá el único problema estriba en el suministro publicitario, no en el informativo. Con televisoras ligadas a los periódicos, como se hizo en muchos países con la radiodifusión, la concurrencia no existiría. Se da, precisamente, cuando las televisoras estatales o paraestatales han empezado a aceptar anuncios ${ }^{5}$. La defensa de la prensa, según notaba Terrou, era la publicidad ${ }^{6}$. Ante tal situación, la coexistencia del medio impreso con el audiovisual depende de su capacidad para adaptarse, sin perjuicio de que de alguna manera aquella pérdida de ingresos les sitúe en difícil postura?

La radio, no barrida por la televisión, no sólo coexiste, sino que se ha visto vigorizada tras la conversión del receptor en utensilio. Se ha pasado del aparato convertido en mueble, al aparato no menos accesible que la estilográfica o el reloj de pulsera. Algunos estudiosos señalan que la radio representa un papel de «aperitivo» ${ }^{8} \mathrm{y}$, por consiguiente, en vez de perjudicar a los demás medios los hace buscar.

Por eso, cada vez importa más la coordinación de los distintos medios que coexisten. Un autor italiano se queja de que los diarios de aquel país parezcan hechos para hacer perder tiempo al lector mientras los anglosajones y los japoneses tratan de ahorrárselo ${ }^{9}$. Es también evidente que, a pesar de los mejores transportes, la distribución veloz no basta a compensar ciertas propuestas de regionalización. Cuando la televisión es del todo nacional, la prensa ha de dar mayor espacio a lo regional, y si finalmente avanza una nueva televisión por cable, tendríamos en ella un complemento de contenidos.

\section{Concurrencia}

Si nos referimos al ámbito noticiero, la concurrencia entre la televisión y la prensa ha de salvarse por esta última, apoyando lo que desde años atrás se le pedía: el reportaje, y sobre todo el reportaje en profundidad. Sólo

- En la Alemania Federal se hicieron estudios muy tempranamente. Cfr. Zeitschriftsverlag und Zeitungsverlag, 15 de mayo de 1964. En diciembre de ese año, en Bad Godesberg hubo una reunión para oír a expertos como Arnold GeHLen, profesor de Sociología en Aquisgrán, y Walter Leizner, de Derecho público, en Munster.

' Cf. Guenter B. Krause-Ablass, Zur Koexistenz von Presse und Fernsehen, considera los aspectos jurídico-constitucionales en el número 10 del Anuario de la Sociedad Sociológica Hamburguesa (Hamburger Jahrbuch fuer Wirtschafts-und Gesellschaftspolitik), Tubinga, 1965.

"F. Terrou, "La presse de la Cinquième république", en Gazette, 8, 1962.

7 Los diarios holandeses, tras la autorización de la publicidad televisual (2 de enero de 1967), son indemnizados con parte de los ingresos, es decir, sobre el sobrante de la cantidad presupuestada para el funcionamiento.

${ }^{8}$ Frase de Alf Schrottz-Christensen, redactor-jefe del Aalborg Stiftstiaende, en informe de la Federación Internacional de Empresas, 1974.

9 Cf. Gaetano Fusaroli, Giornali in Italia, Roma, 1974. 
cabe reflexionar de cara a lo escrito: ante la imagen reaccionamos irracionalmente. Mientras ya en un primer golpe de vista el periódico calibra la noticia, la televisión nos da siempre las noticias a toda plana. La tipografía y el lugar ocupado por la información impresa son datos que no se encuentran en la televisión. Esta, si quiere subrayar tiene que insistir, con lo que algunas veces consigue efecto contrario.

El diario, cercado por la radio y la televisión, ha de mostrarse dócil a las necesidades de sus lectores. El estudio de las audiencias, tradicional en la radio y en la televisión, está siendo feliz y fértilmente utilizado por las empresas editoras. El último simposio parisién de la Federación Internacional de Empresas Periodísticas ha expresado en sus contribuciones y debates de qué modo los lectores permanecen y aún cómo pueden aumentarse ${ }^{10}$. Se pierden o se han perdido por el precio creciente, el también creciente número de títulos y la competencia de la radio y de la televisión. En conjunto, la situación resulta mundialmente equilibrada, aunque se compruebe una pérdida de difusión superior a la tasa de aumento. La conclusión sobre el futuro miró precisamente a ese estudio del estilo de vida de los lectores "como motor del cambio en un periódico»". Los periodistas se esfuerzan para que cada instrumento mantenga su vigencia y para ello importa estudiar los casos concretos: si hay sólo televisión con programa nacional no es lo mismo que si la televisión aborda programas regionales. Lo que siempre queda es, generalmente, lo local.

Más sugerente puede ser el contraste Prensa diaria-Prensa semanal. Yo señalé hace ya algunos años ${ }^{12}$ que veía formarse dos públicos distintos: e] tradicional de la prensa cotidiana (que incluso el domingo sigue los suplementos de los diarios) y el nuevo público de la radio, la televisión y las revistas ilustradas. El hecho universal está también justificado por los datos que muestran que la circulación de las revistas gráficas aumenta con la extensión de la televisión: ¡iríamos hacia un público audiovisual! La tendencia puede acentuarse con la participación social de las nuevas generaciones, acostumbradas a la televisión desde su infancia. De ahí esos esfuerzos en llevar el diario a la escuela y acostumbrar a los niños a la lectura de las noticias,

10 IV Simposio de la Federación de Empresas, París, 17-19 noviembre 1976, sobre "Management and Marketing". Particularmente pertinentes la introducción al tema del holandés Van Neerven y el estudio del director de publicidad del Times Michael S. Mander. Knox-Peebles expuso la significación de las encuestas relativas a la difusión y Lake un caso práctico con interés para ciertas regiones españolas: la difusión de un periódico sobre una zona turística del sur de Florida. Sobre la base de la presencia del A., el Consejo Nacional de Prensa ha distribuido a sus miembros un informe sobre dicho simposio.

En el Vo Simposio, Montecarlo, 27-28 octubre 1977, se abordó la planificación empresarial y se insistió en "la conquista de los lectores", lo que exige nuevos responsables que unan el "management" con el periodismo.

"Michael S. MANDER, Consumer attitude and publisher's product policy: the role of research as a stimulus to change, Comm. al citado simposio, Mimeogr.

12 Juan Beneyto, Información y sociedad, Madrid, 1970, pág. 189. 
a fin de que no se pierda el hábito de leer. El tema del público me parece, por tanto, fundamental. Es preciso ayudar, por la educación, a que se mantenga una concurrencia que favorece el pluralismo y nos prepara para sentir el gusto por la libertad.

De ahí que el mantenimiento de la radio, la presencia de la televisión y el auge de la prensa ilustrada influyan sobre el contenido de los periódicos impresos; no solamente sobre la colocación de las noticias, sino sobre la totalidad del producto. La observación de los periódicos de la Europa Occidental, una vez establecida la Radiotelevisión, me parece expresiva. De ella resultan fáciles emparentamientos: el paso de los editoriales al interior, las crónicas sociales (aunque a veces la imitación es a la inversa, como en el programa «Gente» de nuestra Televisión, que recuerda al «People» del International Herald Tribune). La comparación con lo que pasa en la Europa Oriental me parece igualmente interesante: con una radiotelevisión y una prensa más disciplinadas, ni siquiera hay semanarios de información general ${ }^{13}$.

Otro ejemplo cultural y técnicamente valioso es el enfrentamiento CineTelevisión. Mientras en la producción cinematográfica el contraste inicial ha sido superado con los documentales, en los noticiarios la rendición resultó forzosa, máxime cuando el empresario era el mismo ${ }^{14}$. El noticiario se va y la película complementa: tras la televisión que difunde películas las productoras cinematográficas lanzan al público de la pantalla grandes obras que exigen pantallas mayores y temas que no parecen autorizables para todos los públicos. El Cine se mantiene en las ciudades capitalinas y pierde puntos en las zonas rurales, donde la televisión sigue siendo novedad. Al final hay una cooperación: las grandes cadenas de la televisión norteamericana colaboran en la producción de las películas, dejan que sus copartícipes las exploten año o año y medio, y luego las difunden. (Se acaba así aquella primera exigencia de cinco años de antigüedad para que una película comercial pase a la televisión) ${ }^{15}$.

Una curiosa consecuencia de esta generalización del cine por medio de la televisión es la revalorización del teatro como medio dirigido a un público escogido. En Norteamérica se advirtió ya, tras el primer auge del nuevo medio, hacia $1957^{16}$, y entre nosotros empieza a mostrarse.

13 La comparación entre las dos Alemanias resulta significativa. Frente al Welt am Sonntag con sus secciones, el Wochenpost. Nada semejante a los Ilustrierte. Típicos los semanarios especializados: Fuer Dich, ilustrado femenino; Junge Welt, de la Federación Juvenil; etc.

is Entre nosotros, la sustitución del noticiario por el documental ha resultado difícil, pues el monopolio de la información filmada con su distribución obligatoria en los cines del país obstaculizó la producción privada de documentales. Así, pues, todo quedó en que el No-Do era sustituido por el Telediario.

is Francia estudió el tema tras el informe DiLIGENT en abril de 1968. Sobre la problemática general, Le Monde 28 de marzo de 1969.

"Cf. Alice Grifrin, "Nuevas tendencias en el teatro norteamericano", en Perspectives, 14 (resumido en Atlántico, 9, Madrid, 1958). 
En fin, aunque en un principio el libro resultó afectado por la televisión y la radio, en tanto que había sido estimulado, como mecanismo que exigía una previa alfabetización, por la prensa; ahora puede decirse que la concurrencia de tales medios mejora su imagen. No sólo se venden más libros al tratar de su propia temática el Cine o la Televisión, sino que el libro se ve generalmente como complementario. La televisión no sustituye al libro, y cuando lo ha señalado o. utilizado ha hecho agotar rápidamente las tiradas.

La Publicidad y las Relaciones públicas constituyen algo más que cooperadores económicos: son estímulo e incitación de los demás medios.

\section{Coordinación}

En la I Semana de Estudios sobre la Prensa, organizada en Sitges por el Instituto de Estudios Sociales de Barcelona, dio Bernard Voyenne la que podríamos llamar «fórmula mágica» para la coordinación de los medios de comunicación considerados concurrentes ${ }^{17}$. Lo mismo que se creyó que con el automóvil abandonaríamos el ferrocarril y con el avión dejaríamos el coche..., y ahora tomamos el tren, el coche o el avión según las distancias; habría de pasar con la radiotelevisión, el cine, la prensa o las revistas. Adviértase que incluso acabamos por meter el coche en el tren y en el navío...

Quizá, sin embargo, las cosas no sean tan sencillas: para que la coexistencia sea coordinable me parece que es previa su complementariedad.

También hay que advertir la presencia del hombre de un solo medio, como antes se hablaba del hombre de un solo periódico o de un solo libro. Ya he señalado mi hipótesis de dos públicos diferentes: de la radiotelevisión y la revista ilustrada y del periódico diario y la revista informativa o doctrinal...

Hagamos un poco de historia.

La primera amistad entre la Prensa y la Radio arranca del momento en que los diarios encontraron material informativo en el nuevo medio, al ser noticia la Radio y sus gentes. También ayudó el factor económico: los anuncios de aparatos receptores. Cuando empezó a formarse un público de la Radio, se advirtió que ese público sentía interés en complementar el simple flash que era la información radiodifundida. La Radio, además, no siempre se escucha: se oye, suena, y tiene no poco de ese rumor soñado que hace urgir la confirmación: ver en letras de molde lo que se ha oído al través de las ondas. La enemistad inicial (que llegó a la presión sobre las agencias noticiosas para que no vendiesen noticias a las emisoras de radio) fue cancelada. Aun cuando no se integrasen en una misma empresa, ya dejaron de. mirarse como competidores. Alguna vez hubo todavía fricciones: tal el caso

17 Voyenne en "I Semana Internacional de la Prensa", Barcelona, 1963. 
de las emisiones deportivas dominicales. Ultimamente se llega a acuerdos para trabajar en común ${ }^{18}$.

Lo mismo ha venido a acontecer con la televisión. Un estudio de la Escuela Thopson rechazaba, ya en 1968, la idea de que la televisión fuese un duro competidor: no es un rival, sino todo lo contrario, pues induce a la gente a comprar periódicos ${ }^{19}$. (Siempre que se limite a su función... debemos advertir.)

El problema no está, pues, en los medios, sino en quienes preparan la expresión y el contenido, la maqueta y el flash.

El periodista de la televisión nos lleva al lugar del acontecimiento, pero no puede explicarnos su por qué. El famoso comentarista Walter Cronkite escribe: «Podemos dar al público noticias, pero sólo las noticias del día sin los comentarios que exige aquél. La limitación de tiempo es terrible: durante una media hora, leyendo seguido todas las noticias y añadiéndoles unas pocas imágenes podríamos dar apenas la primera plana del New York Times» ${ }^{20}$. Ante estos hechos, el periodista de la prensa impresa debe saber cuál es su tarea, para complementar la información recibida por el audiovisual. El crecimiento de la población y la generalización de la instrucción pública exige un producto mejor. Lo son, generalmente, los diarios contemporáneos. (Vale la pena acudir a las hemerotecas y contemplar aquella prensa que juzgábamos ejemplar hace veinte años.)

Hay, además, cosas que no van bien en televisión y se ven mejor en la prensa: ahí están los anuncios que exigen detalle, no sólo los anuncios por palabras, sino la cartelera de espectáculos, las ofertas de los grandes almacenes y, en fin, todo lo que se completa con cifras. A la televisión corresponden plenamente otros llamamientos: los productos de marca.

Prensa y Televisión parecen tener que vivir complementándose. Si la llamada a la razón es obligada en todo hombre libre, nada sirve a la libertad como una Prensa donde la información nos llegue como un llamamiento a reflexionar sobre los acontecimientos ${ }^{21}$. Por eso es grave la responsabilidad de los gobernantes, que deben procurar que se mantenga no sólo el pluralismo de cabeceras o de cadenas, sino de los medios o instrumentos en su conjunto.

${ }^{18}$ En un ejemplo próximo: acuerdo entre France Soir, Le Point y la emisora Europa núm. 1, octubre 1974.

${ }^{19}$ Scope, diciembre 1968: "Television generates news".

${ }^{20}$ Citado en el informe anual de la Federación de Empresas Periodísticas, 1974. También puede señalarse una curiosa observación del servicio internacional de la A.N.P.A.: Se os pide que representéis el cerebro humano como un ordenador gigante, tal como los sabios lo explican: el ordenador más complejo y más costoso; pues rápidamente podéis comprobar que la palabra escrita puede programar la inteligencia humana mucho más eficazmente que la palabra hablada. Y ello es comprensible porque mientras se pronuncian o escuchan ciento cincuenta por minuto, pueden leerse tranquilamente quinientas...

${ }^{21}$ Cf. J. L. Servan-Schreiber, "Les journaux 20 ans après la TV.", en Le Monde 1 de octubre de 1974 . 
Por lo que toca a nuestros medios, la relación Cine-Televisión no sólo se ha afirmado como cooperación en Norteamérica, sino también en Europa, donde los estudios de la Bavaria, en Munich, dan otro ejemplo, incluso por encima de las fronteras ${ }^{22}$. El teatro ha llegado igualmente a coproducciones ${ }^{23}$...

Si, como señalaba en una de sus actividades póstumas André Malraux, la próxima alfabetización será la enseñanza audiovisual, ninguna ley de libertades públicas conseguirá nada si la sociedad no se adueña del «más poderoso instrumento de libertad o de servidumbre que ha concebido el espíritu humano» ${ }^{24}$. La socialización de la Televisión es así la primera exigencia del hombre que aspira a seguir siendo protagonista de la Historia.

Cuantos trabajan en la información han de enfrentarse con la realidad tecnológica sin desdeñar ese mundo de los valores cuya supervivencia exige cooperación. Frente a la concurrencia hay que imponer la cooperación, precisamente por medio de una ordenación que sitúe la complementariedad.

Acuerdos entre la Bavaria y la ORTF, así como con la RAI. Bavaria produce más de trescientas horas de obras dramáticas y de series de tipo folletín.

${ }^{23}$ En Francia se representan en teatro algunas obras preparadas para la televisión con los mismos intérpretes y directores, con el consiguiente ahorro.

${ }^{24}$ Palabras ante la Comisión Parlamentaria de Leyes sobre las Libertades Públicas, 12 de mayo de 1976 (Le Monde del 14). 
DOCUMENTACION 